\title{
Equilibrium discovery and preopening mechanisms in an experimental market
}

\author{
Bruno Biais ${ }^{1}$ \\ Christophe Bisière ${ }^{2}$ \\ Sébastien Pouget ${ }^{3}$
}

January 6, 2009

\begin{abstract}
${ }^{1}$ Toulouse School of Economics (IDEI-GREMAQ), Manufacture des Tabacs, 21, Allée de Brienne, 31000 Toulouse. Email: biais@ cict.fr. Phone: +33 (0)5 61128598.

${ }^{2}$ Toulouse School of Economics (IDEI), Manufacture des Tabacs, 21, Allée de Brienne, 31000 Toulouse. Email: bisiere@univ-tlse1.fr. Phone: +33 (0)5 61128576.

${ }^{3}$ Toulouse School of Economics (IDEI), Manufacture des Tabacs, 21, Allée de Brienne, 31000 Toulouse. Email: sebastien.pouget@univ-tlse1.fr. Phone: +33 (0)5 61128572.

We gratefully acknowledge the financial support of the Europlace Institute of Finance and ENABLE. Many thanks for insightful comments to Jocelyn Donze, Thomas Mariotti, Jérôme Renault, Vincent Remay and participants in the joint UCL-Birbeck theory seminar, the University of Strasbourg seminar, the Mannheim University Symposium on Behavioral Economics, the joint CSIO IDEI conference in Northwestern, the third Annual Central Bank Workshop on the Microstructure of Financial Markets held at the Magyar Nemzeti Bank in Budapest, the second European Workshop on Experimental and Behavioral Economics in Lyon, the Kogod Research Seminar, American University, the conference on Investment strategies and financial market dysfunctionality at the Paul Woolley Centre, the European Meeting of the Economic Science Association in Lyon, and the Micro Lunch Workshop at the Cowles Foundation, in particular Bashkar, Gary Charness, Terry Hendershott, Johannes Horner, Rob Porter and Ernesto Reuben.
\end{abstract}




\title{
Equilibrium discovery and preopening mechanisms in an experimental market.
}

\begin{abstract}
We experimentally analyze equilibrium discovery in i) a pure call auction, ii) a call auction preceded by a nonbinding preopening period, and iii) a call auction preceded by a binding preopening period. We examine whether a preopening period can facilitate coordination on the Pareto dominant equilibrium. During the nonbinding preopening period, traders tend to place manipulative orders. After observing such orders, participants learn to distrust cheap talk and coordinate less on Pareto dominant outcomes. In contrast, we find that, when preopening orders are binding, they improve the ability to coordinate on high gains from trade.
\end{abstract}

Keywords: Cheap talk, experimental markets, equilibrium discovery, preopening period. 


\section{Introduction}

Discovering equilibrium prices and orders at the opening of stock markets is a difficult task, especially because liquidity externalities can generate equilibrium multiplicity. ${ }^{1}$ To facilitate price discovery and coordination on high liquidity, several bourses start with a preopening period where investors can place orders, and indicative prices are set and disseminated. ${ }^{2}$ But, to the extent that preopening orders can be cancelled, traders can use them to manipulate the market. ${ }^{3}$ This could prevent the preopening from facilitating coordination. Market designers have introduced certain features to deter such manipulation. For example, as is the case on Xetra, the German computerized stock exchange, the exact time of the opening can be random. ${ }^{4}$ Or cancellations can be costly. This paper offers an experimental investigation of three market mechanisms, inspired by those prevailing in actual stock exchanges.

We study a simple trading game where, depending on parameter values there is one or two pure strategy Nash equilibria. In the first case, corresponding to low liquidity, the unique equilibrium generates low gains from trade. In the second case, one of the pure strategy equilibria involves low liquidity and low gains from trade, while the other involves high liquidity and high gains from trade. The former equilibrium is risk dominant, while the latter is Pareto dominant. In that context, coordinating on equilibrium is likely to be difficult. ${ }^{5}$ We study under what conditions a preopening period can facilitate such coordination and foster high gains from trade.

Our experimental investigation of preopening mechanisms is directly in line with analyses of preplay communication and cheap talk (see Cooper, DeJong, Forsythe and Ross (1992), Crawford (1998), Charness (2000), Clark, Kay and Sefton (2001) and Blume and Ortmann (2007)). ${ }^{6}$ The first major difference between our analysis and this literature is that we compare three market mechanisms:

- A pure one-shot call auction where buyers and sellers submit limit orders and the uniform price is set to clear the market.

- A call market preceded by a nonbinding preopening period. In this treatment, the call market is held twice in each replication of the experiment. At time 0 , participants place nonbinding

\footnotetext{
${ }^{1}$ See Pagano (1989), Admati and Pfleiderer (1988) and Dow (2004).

${ }^{2}$ Biais, Hillion and Spatt (1999) document the information content of these prices in the Paris Bourse.

${ }^{3}$ Davies (2003) investigates whether preopening trades on the Toronto Stock Exchange are manipulative.

${ }^{4}$ In the description of the Xetra market model, one can read: "The call phase has a random end after a minimum period in order to avoid price manipulation" (Deutsche Börse, 2004, page 20).

${ }^{5}$ Van Huyck et al (1990) and Battalio, Samuelson and Van Huyck (2001) document experimentally the occurrence of coordination failures.

${ }^{6}$ While the above mentioned papers, like ours, consider a symmetric information environment, Forsythe et al (1999) consider the adverse selection case. They find that, even in that context, preplay communication can improve efficiency. Crawford (1998) offers a survey encompassing both symmetric information and private information analyses.
} 
orders and purely indicative prices are set and disseminated. But no trade takes place. Then these orders are cancelled and, at time 1, participants place firm orders, which are taken into account to determine the price and the trades.

- A call market preceded by a binding preopening period. In that game, traders have the option to place orders at time 0 . If they do so, those orders are firm and cannot be cancelled. Alternatively, the traders can wait until time 1 to participate in the call auction.

While our experimental setting is admittedly extremely simple and stylized, these three market mechanisms capture some salient features of the opening of real stock exchanges, namely the ability to place orders prior to the opening and the fact that canceling these orders can be more or less difficult or costly. Thus, comparing the performance of our experimental market structures can offer some insights useful for the design of exchanges.

The second major difference between our paper and previous literature is that we study the effect of history on participants' behavior. $^{7}$ Some traders first start with a game where potential equilibrium gains from trade are high, and then experience a situation with low liquidity and low gains from trade. Other participants experience the opposite sequence. The idea is that in real economic situations, and in particular stock exchanges, market conditions and potential gains from trade vary through time. We designed our experiment to generate, in a simple way, such variability. As market conditions change, the set of equilibria is altered and so is the scope for coordination and gains from trade. Our experiment offers an opportunity to study how participants exposed to different histories form different beliefs and realize different outcomes.

Our experiment was run in the Toulouse University laboratory, with 156 master students, who each played 15 replications of the game and received financial rewards proportional to their gains. Interactions were computerized and anonymous, and participants were randomly matched at each period to rule out any repeated game effect.

Our main experimental results are the following. When there is a unique equilibrium with low liquidity, there is no scope for coordination on high gains from trade. Yet, with a nonbinding preopening, traders initially send manipulative orders during the preopening, falsely promising to supply plentiful liquidity. Then they betray these promises in the call auction. ${ }^{8}$ After observing such behavior, participants learn to mistrust nonbinding preplay communication. This results in limited gains from trade, even when the market then moves to the situation where there is a Pareto dominant equilibrium with high gains from trade. Hence, the opportunity to engage in preplay

\footnotetext{
${ }^{7}$ Schmidt et al (2003) also study the role of history and the impact of parameter changes on behaviour. But they consider only coordination games, while we also consider prisoners' dilemmas. And they don't consider preplay communication.

${ }^{8}$ The analysis of Charness (2000) also covers the case of a prisoner's dilemma. In that case, he finds that cooperation is announced $79 \%$ of the time but played only $10 \%$ of the time. Our results are in line with his findings.
} 
communication during the nonbinding preopening period does not enhance coordination on the Pareto dominant equilibrium. In contrast, with a binding preopening period, traders cannot send manipulative orders. Correspondingly, we find that the binding preopening mechanism enhances coordination on the high liquidity and high gains from trade equilibrium.

Our results suggest that preplay communication mechanisms can be fragile. Underscoring this fragility is one contribution of our paper relative to the previous literature. Cooper, DeJong, Forsythe and Ross (1992), Charness (2000) and Blume and Ortmann (2007) find that, in a cooperation game, nonbinding preplay communication fosters coordination on the Pareto dominant equilibrium when the parameters of the game are constant. In contrast, we consider the case where participants face varying parameter constellations, some for which coordinating on Pareto dominant outcomes is feasible, others in which such win-win situations are not equilibrium outcomes. We show that the latter situation generates bitter experiences, which then precludes coordination via nonbinding preplay communication. ${ }^{9}$

Another contribution of our paper is to suggest an alternative mechanism to pure cheap talk, in which this problem is mitigated. In our experiment, when preopening orders are binding, coordination on the Pareto dominant equilibrium is often observed. And this is robust to bad initial conditions, with low initial gains from trade. In this market structure, indeed, participants don't have the opportunity to make false promises and then breach them. Thus, they can't loose trust in the possibility to coordinate on win-win situations. And they take advantage of the sequencing of the game to coordinate on high gains from trade. The corresponding high performance of the market with a binding preopening period, observed in our experiment, is in line with the predictions of the trembling hand equilibrium concept.

The next section describes our trading game, its equilibria and our hypotheses. Section 3 presents the experimental design. Section 4 presents the results. Section 5 concludes. The instructions given to the participants are in the appendix.

\section{The trading game}

In financial markets, opening prices are often set in uniform price auctions, referred to as call auctions. This is the case, for instance, in the two major European stock markets: Euronext and Xetra, as well as in other bourses throughout the world, such as, e.g., the Brazilian stock exchange. Recognizing that equilibrium discovery is a difficult task, several market organizers have designed

\footnotetext{
${ }^{9}$ Note also that, in our setup, preplay announcements to play the Pareto dominant equilibrium are not self-enforcing in the Aumann (1990) sense. This differs from the case studied by Cooper et al (1992). Clark et al (2001) also study preplay communication in a setting where announces are not self enforcing. They find that cooperation is announced $81 \%$ of the time, but played only $42 \%$ of the time. Our results on the nonbinding preopening period are consistent with their findings.
} 
preplay communication mechanisms. Thus, Euronext or the Brazilian and the Australian stock exchanges feature a preopening period whereby traders can submit or cancel limit orders and tentative prices are set (see Biais, Hillion and Spatt, 1999). In this section, we present a stylized trading game designed to capture some important features of such markets. There is one buyer and one seller who differ in terms of their private valuation of the asset. The buyer assigns value $v=4$ to the asset, up to $\bar{q}$ units, and then 0 . The cost to the seller of providing the good is $c=0$ up to $\bar{q}$ units, and then infinity. Potential gains from trade for $\bar{q}$ units are: $(v-c) \bar{q}=4 \bar{q}$. The players know the structure and the parameters of the game, i.e., we consider a complete information setting.

\subsection{The call auction without preopening}

In the pure call auction without preopening period, buyers and sellers simultaneously post schedules of limit orders, and thus demand and supply curves. Once the orders have been placed, the supply and demand curves are confronted and the price is set to maximize the number of shares traded. This is a uniform price double auction, i.e., all orders are executed at the same price. If more than one price maximizes volume, then we assume the transaction price is an arithmetic average of the candidate prices.

We study a very simple form of this market. One buyer and one seller are matched. Each trader has the choice between two schedules of limit orders only. The buyer can opt for a rather unaggressive schedule, denoted by $B 1$. This involves a limit order to buy 8 units if the price is not above 2 , and another order to buy $\bar{q}-8$ additional units if the price is not above 1 . Obviously, we assume that $\bar{q}>8$. Alternatively, he can opt for a more aggressive schedule, for which demand is shifted upward and which we denote by $B 2$. This involves a limit order to buy 8 units if the price is not above 3 , and another order, to buy $\bar{q}-8$ units if the price is not above 2 . Symmetrically, the seller can choose between two schedules: $S 1$ and $S 2$. The former involves a limit order to sell 8 units if the price is not below 2 and another order to sell $\bar{q}-8$ units if the price is not below 3 . The latter involves a limit order to sell 8 units if the price is not below 1 and another order, to sell $\bar{q}-8$ units if the price is not below 2. As an illustration, the supply and demand curves corresponding to these schedules of limit orders for $\bar{q}=11$ are plotted in Figure 1. The players can also choose not to submit any orders. This is denoted by $S 0$ and $B 0$ for sellers and buyers, respectively.

If both traders opt for aggressive limit orders ( $S 2$ and $B 2$ ), the market clearing price is 2 and the corresponding volume is $\bar{q}$. If both traders opt for less aggressive orders ( $B 1$ and $S 1$ ), the price is still 2 , but trading volume is equal to 8 . If the buyer is aggressive, but not the seller ( $B 2$ and $S 1)$ then trading volume is 8 and the price is pushed up to 2.5. If the seller is aggressive, but not the buyer ( $B 1$ and $S 2$ ) then again trading volume is 8 , but the price is pushed down to 1.5. Thus, each trader faces a trade-off: He can choose to place an aggressive schedule, potentially generating 


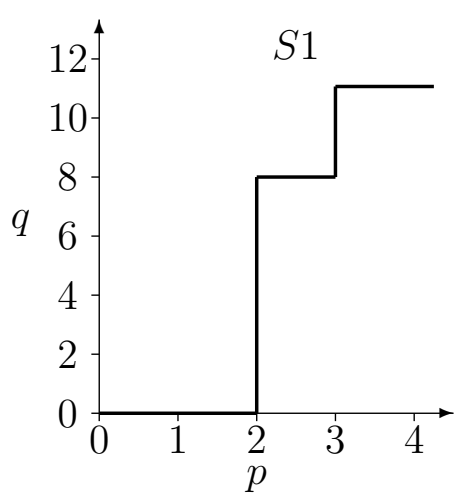

(a) Supply curve $S 1$

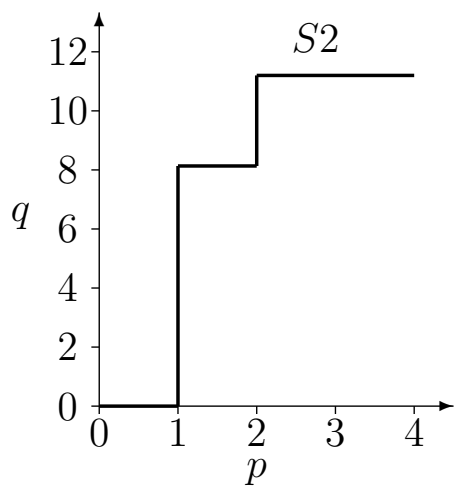

(c) Supply curve $S 2$

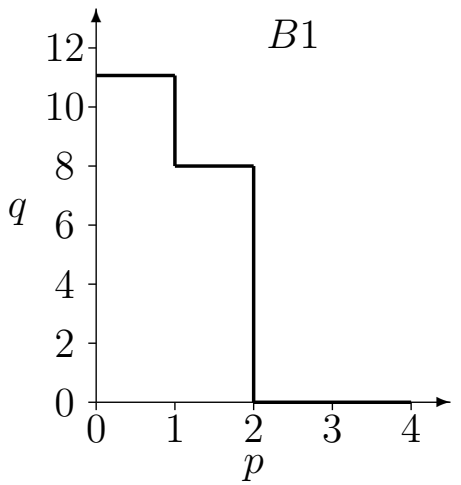

(b) Demand curve $B 1$

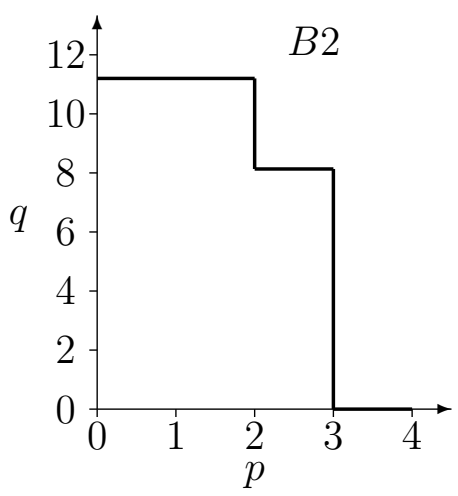

(d) Demand curve $B 2$

Figure 1: Supply and demand curves when $\bar{q}=11$. 
greater gains, but at the risk of an adverse price move. This risk depends on whether or not the other trader aggressively provides liquidity. This can be interpreted as liquidity risk.

Discarding $S 0$ and $B 0$, which are weakly dominated, the situation faced by traders in the pure call auction can be represented as a normal form game, where the payoff of the seller is the first number in each cell, and the payoff of the buyer is the second number in each cell:

\begin{tabular}{l|c|cc|}
\multicolumn{3}{c}{} & \multicolumn{2}{c|}{ Buyer: } \\
\cline { 2 - 4 } Seller: & & $B 1$ & $B 2$ \\
\cline { 2 - 4 } & $S 1$ & $(16,16)$ & $(20,12)$ \\
& $S 2$ & $(12,20)$ & $(2 \bar{q}, 2 \bar{q})$ \\
\hline
\end{tabular}

In the off-diagonal cells, the trader with the less aggressive schedule earns greater gains than his or her counterparty. Note also that, since $\bar{q}>8$, the pair of actions which maximizes the total gains from trade is $(S 2, B 2)$. But will this allocation arise in equilibrium? The answer is given in the next proposition (whose proof is obvious and omitted).

Proposition 1 Consider the pure call auction. No trade, i.e., $(S 0, B 0)$, is a Nash equilibrium, but it involves weakly dominated strategies. If $\bar{q}<10$, then $(S 1, B 1)$ is the only undominated Nash equilibrium. If $\bar{q}>10$, there are (on top of the no-trade equilibrium) two pure strategy equilibria: $(S 1, B 1)$ and $(S 2, B 2)$, as well as a mixed strategy equilibrium whereby, each trader selects the aggressive schedule, $S 2$ or B2, with probability $2 /(\bar{q}-8)$.

In our experiment we want to include both the prisoner's dilemma situation, where the unique Nash equilibrium is $(S 1, B 1)$, and the cooperative situation whereby both $(S 2, B 2)$ and $(S 1, B 1)$ are equilibria. Thus, we will consider two possible parameter values: $\bar{q}=9$ and $\bar{q}=11$. In the latter case, $(S 2, B 2)$ is Pareto dominant while $(S 1, B 1)$ is risk dominant. ${ }^{10}$

\subsection{The call auction with a preopening period}

While some stock markets operate without formal preopening period, in other bourses there is a preopening period during which traders can enter limit orders and indicative prices are set and disseminated. There are no trades at these prices, but investors can observe them. This mechanism can be useful if, by observing the indicative prices, investors can progressively coordinate on an equilibrium. But it's not clear whether such preplay communication can deliver useful and reliable information. After all, if traders can costlessly place and cancel orders, they have no clear incentives to reveal their true trading intentions and can attempt to manipulate the market. To cope with

\footnotetext{
${ }^{10}$ Suppose the buyer has no clue about the actions of the seller and assigns equal probability to the two possible actions $S 1$ and $S 2$. Then, when $\bar{q}=11$, the expected utility of the buyer if he plays $B 1$ is: $\frac{1}{2} 16+\frac{1}{2} 20=18$, while his utility if he plays $B 2$ is: $\frac{1}{2} 12+\frac{1}{2} 22=17$. Hence, the buyer prefers to play $B 1$.
} 
this problem, market organizers have designed preopening periods where it can be unattractive or difficult to cancel manipulative orders. This can involve forbidding cancellations, imposing costs for traders canceling orders, or opening the market at a random point in time. To study these issues we consider two types of preopening in our simple setup:

- The first preopening mechanism we consider is a pure cheap talk game, involving nonbinding orders. At time 0 the buyer and the seller can enter orders $S 0, S 1$ or $S 2$ and $B 0, B 1$ or $B 2$. These orders are matched and an indicative price is set, at which there is no trade. All investors observe the outcome of this preopening round. Then, at time 1 , the preopening orders are cancelled and the traders have a new opportunity to place orders. These time 1 orders are those which will be used to set the opening prices at which actual trades will occur.

- The second preopening mechanism involves binding orders. It is designed to capture, in a simple way, attempts by market designers to curb manipulation and noisy preopening orders. At time 0 the traders can choose to place limit orders $S 1$ or $S 2$ and $B 1$ or $B 2$. Alternatively, they can choose to place no order (denoted by $S 0$ and $B 0$ ) and wait for $t=1$. The outcome of this preopening round is observed by all. The difference with the nonbinding preopening is that when traders have placed orders $B 1, S 1, B 2$ or $S 2$ at $t=0$, they cannot cancel these initial orders and place new ones. On the other hand, traders who have not placed orders at $t=0$ have the opportunity to place orders at $t=1$.

How does the presence of this preopening phase alter behavior and outcomes in our simple trading game?

When preopening orders are nonbinding, they can be discounted as pure noise by the players. In that case, actions at $t=0$ are irrelevant, and equilibria at $t=1$ are the same as in the market without preopening. On the other hand, players can use preopening orders as communication devices, and in that case there may be a link between orders placed at $t=0$ and orders placed at $t=1$. For example, the agents could agree that, if they played $B 2$ and $S 2$ at $t=0$ then they should also play play $B 2$ and $S 2$ at $t=1$. A more complex scheme would be for the agents to use a jointly controlled lottery, as in Aumann, Maschler and Stearns (1968). For example, the players could mix between $B 1$ and $B 2$ (or $S 1$ and $S 2$ ) at $t=0$ with equal probability. Then, at $t=1$, they would coordinate on $(B 2, S 2)$ if they played on the diagonal, i.e., $(S 1, B 1)$ or $(S 2, B 2)$ at $t=0$. And they would coordinate on $(B 1, S 1)$ if they played off the diagonal, i.e., $(S 1, B 2)$ or $(S 2, B 1)$ at $t=0$. Whatever the equilibrium prevailing in the market with a nonbinding preopening, the same equilibrium actions can be observed at $t=1$ as without preopening. This is stated in the next proposition: 
Proposition $2(B 0, S 0),(B 2, S 2),(B 1, S 1),(S 1, B 2)$ and $(S 2, B 1)$ at $t=1$ are equilibrium outcomes in the call market preceded by a nonbinding preopening.

With binding preopening orders, when $\bar{q}=9$, there are only two equilibria: $(S 0, B 0)$ and $(S 1, B 1)$, and it does not matter whether the agents place their orders at time 0 or at time 1 . But, when $\bar{q}=11$, things are more involved.

To analyze this case, we focus on subgame perfect Nash equilibria. Thus, we rule out actions which are strictly dominated at certain nodes of the game. To do this, we first consider the case where, at time 0 , the buyer played $B 1$ and the seller chose to wait (i.e., played $S 0$ ). Then, playing $S 2$ or $S 0$ at time 1 would be strictly dominated by the play of $S 1$. Second, we turn to the case where, at time 0 , the buyer played $B 2$ and the seller chose to wait. Then, the play of $S 1$ or $S 0$ at time 1 is strictly dominated by $S 2$. Symmetric arguments apply when the buyer chose to wait while the seller played either $S 1$ or $S 2$ at time 0 . Thus, we can state the following lemma:

Lemma 1 When $\bar{q}=11$ in the market with a binding preopening, the set of choices for the seller that are not strictly dominated is:

- Play $S 0$ at $t=0$.

- Play $S 1$ at $t=0$.

- Play $S 2$ at $t=0$.

- Wait at $t=0$ and then respond $S 1$ if $B 1$ or $B 0$ was played at time and $S 2$ if $B 2$ was played at time 0. Denote this by $\Sigma_{1}^{S}$.

- Wait at $t=0$ and then respond $S 1$ if $B 1$ was played at time and $S 2$ if $B 2$ or B0 was played at time 0. Denote this by $\Sigma_{2}^{S}$.

Similarly the set of choices that are not strictly dominated for the buyer is $B 0, B 1$ or $B 2$ at time 0 and $\Sigma_{1}^{B}$ or $\Sigma_{2}^{B}$.

Furthermore, note that no trade, i.e., $(S 0, B 0)$ at time 0 and time 1 , cannot be a subgame perfect Nash equilibrium. Suppose the buyer anticipates the seller to wait at time 0 , and then to respond $S 0$ at $t=1$ to the play of $B 0$ at $t=0$. Then the buyer is better off playing $B 2$ at $t=0$.

Thus, to analyze the subgame perfect equilibria in the market with a binding preopening, one can focus on the following normal form game:

\begin{tabular}{c|cccc|}
\multicolumn{1}{c}{} & \multicolumn{1}{c}{$S 1$} & $S 2$ & $\Sigma_{1}^{S}$ & $\Sigma_{2}^{S}$ \\
\cline { 2 - 5 }$B 1$ & $(16,16)$ & $(20,12)$ & $(16,16)$ & $(16,16)$ \\
$B 2$ & $(12,20)$ & $(22,22)$ & $(22,22)$ & $(22,22)$ \\
$\Sigma_{1}^{B}$ & $(16,16)$ & $(22,22)$ & $(16,16)$ & $(20,12)$ \\
$\Sigma_{2}^{B}$ & $(16,16)$ & $(22,22)$ & $(12,20)$ & $(22,22)$ \\
\cline { 2 - 5 } & & &
\end{tabular}


Inspecting this normal form, one can see that the game admits seven subgame perfect pure Nash equilibria, as stated in the following proposition:

Proposition 3 In the market with a binding preopening when $\bar{q}=11$, there are seven subgame perfect pure Nash equilibria:

- $(S 1, B 1)$ at $t=0$,

- $(S 2, B 2)$ at $t=0$,

- S2 at $t=0$ and $\Sigma_{1}^{B}$,

- S2 at $t=0$ and $\Sigma_{2}^{B}$,

- B2 at $t=0$ and $\Sigma_{1}^{S}$,

- B2 at $t=0$ and $\Sigma_{2}^{S}$,

- $\left(\Sigma_{2}^{S}, \Sigma_{2}^{B}\right)$.

The mixed strategy equilibria of the game are stated in the next proposition.

Proposition 4 In the market with a binding preopening when $\bar{q}=11$, there are 2 mixed strategies subgame perfect Nash equilibria:

- The buyer mixes between $B 1$ at $t=0$ and $\Sigma_{1}^{B}$, while the seller mixes between $S 1$ at time 0 and $\Sigma_{1}^{S}$.

- The buyer mixes between $B 2$ at $t=0$ and $\Sigma_{2}^{B}$, while the seller mixes between $S 2$ at time 0 and $\Sigma_{2}^{S}$.

Note that, in contrast with the two previous market structures, mixing between $B 1$ and $B 2$ or $S 1$ and $S 2$ at $t=0$ or $t=1$ is not an equilibrium. The intuition is the following. Could the buyer mix between $B 1$ and $B 2$ at $t=0$ ? In that case the seller would be strictly better off playing $S 0$ at $t=0$ and then, at $t=1$, play his best response to the realized action of the buyer. But, anticipating that the seller would wait, the buyer finds it suboptimal to mix at $t=0$. Also, mixing between $B 1$ and $B 2$ cannot arise in equilibrium. If the buyer plans to mix between $B 1$ and $B 2$ at time 1, then he waits at time 0 . Anticipating this, the seller is better off playing $S 2$ at time 0 . Observing that decision, the buyer then finds it suboptimal to mix at time 1.

To sharpen further our analysis of the equilibria of this game, we rely on the notion of trembling hand perfection (Selten, 1975). In the two market structures analyzed above, that concept did not 
rule out any subgame perfect Nash equilibrium. But the market with a binding preopening has a sequential flavour which gives bite to the notion of trembling hand perfection. First note that

playing $B 1$ (resp. $S 1$ ) at time 0 is weakly dominated by playing $\Sigma_{1}^{B}$ (resp. $\Sigma_{1}^{S}$ ). Thus, trembling hand perfection rules out the equilibria involving the play of $S 1$ or $B 1$ at time 0 . Intuitively, if there is a small chance that the seller trembles to $S 2$, then the buyer is better off playing $\Sigma_{1}^{B}$ than $B 1$. This leads to our next proposition.

Proposition 5 In the market with a binding preopening when $\bar{q}=11$, the only trembling hand perfect Nash equilibrium outcome is $(S 2, B 2)$.

Thus, while Nash equilibrium multiplicity arises in the three market structures, the three games have distinct stategic properties. When the preopening is binding there is a unique trembling hand perfect equilibrium outcome, $(S 2, B 2)$. In contrast, in the pure call auction or with a nonbinding preopening period, both $(S 2, B 2)$ and $(S 1, B 1)$ are trembling hand perfect.

\subsection{Hypotheses}

\subsubsection{Dominant strategy equilibrium and trembling hand perfection}

When $\bar{q}=9$, there is a unique undominated equilibrium outcome, whatever the structure of the trading game. Accordingly we posit the following hypothesis:

Hypothesis 1 When $\bar{q}=9$ we expect the outcome of the game to be $(S 1, B 1)$ in the three market structures.

When $\bar{q}=11$, with a binding preopening period there is a unique trembling hand perfect equilibrium outcome. Accordingly we posit the following hypothesis:

Hypothesis 2 When $\bar{q}=11$ we expect the outcome of the game to be $(S 2, B 2)$ with a binding preopening period.

In the lab, Hypothesis 2 may fail to hold if the participants play $(S 1, B 1),\left(S 1, \Sigma_{1}^{B}\right)$ or $\left(B 1, \Sigma_{1}^{S}\right)$, which are subgame perfect equilibria, but not trembling hand perfect. In that sense our experimental design offers a test of the predictive power of the concept of trembling hand perfection in a simple context. 


\subsubsection{Mismatches}

When $\bar{q}=11$, in all the market structures we consider there are multiple subgame perfect Nash equilibria, with different levels of liquidity and gains from trade. And, while some equilibria are Pareto dominant, the Pareto dominated outcome is risk dominant. This could make it more difficult for participants to coordinate on one equilibrium. If the participants fail to achieve such coordination, we will observe frequent mismatches, with outcomes $(S 2, B 1)$ or $(S 1, B 2)$. However, preplay communication can be expected to facilitate coordination. Thus we expect that, when there is a preopening period with nonbinding orders, mismatches should be less frequent than in the pure call market without preopening. Furthermore, we expect mismatches at $t=0$ to be even less frequent when preopening orders are binding since in that case they are not subgame perfect Nash equilibrium outcomes. Thus we posit the following hypothesis:

Hypothesis 3 When $\bar{q}=11$, the frequency of mismatches, whereby the outcome is $(S 2, B 1)$ or $(S 1, B 2)$, should be greatest in the pure call market without preopening and smallest with binding preopening orders.

\subsubsection{Manipulation}

When $\bar{q}=9$, the presence of a nonbinding preopening should have no effect on game outcomes. Participants should realize that at time 1 their opponent will always play $S 1$ or $B 1$, whatever his or her initial order. So they should ignore any other preopening order. At the same time, if participants are unsure whether their opponents conduct such reasoning, they might attempt to manipulate their beliefs. Thus, when $\bar{q}=9$ and the preopening is not binding, they could place misleading orders, for example $S 2$ at time 0, hoping their opponent would naively respond with $B 2$ at time 1 . If the manipulation was successful, the players would opportunistically take advantage of such naive behavior by placing $S 1$ at time 1 . And if the manipulation was unsuccessful it would not be costly to the seller, since it would end up, anyhow, with the equilibrium outcome $(S 1, B 1)$. Thus we posit the following hypothesis:

Hypothesis 4 When $\bar{q}=9$ and there is a preopening period with nonbinding orders, participants will place manipulative orders, $S 2$ or $B 2$ at $t=0$ and then revert to $S 1$ and $B 1$ at $t=1$. But, to the extent that their opponents are rational, the play of $S 2$ at $t=0$ will not increase the frequency of $B 2$ at $t=1$ (and symmetrically on the other side of the market).

This hypothesis is in line with the experimental results of Charness (2000), who studies a prisoner's dilemma with nonbinding preplay communication and finds that players tend to announce cooperation but then play defection. 


\subsubsection{Cheap talk and cooperation}

The nonbinding preopening is in fact a cheap talk mechanism. When $\bar{q}=11$, will such cheap talk foster coordination on the Pareto dominant equilibrium $(S 2, B 2)$ ? Cooper, DeJong, Forsythe and Ross (1992), Charness (2000) and Blume and Ortmann (2007) show experimentally that, in games with multiple Pareto-ranked equilibria, preplay communication fosters coordination on the most efficient one. Farrell (1987) and Farrell and Rabin (1996) offer a theoretical argument to rationalize this. The intuition is the following: Of course, when non equilibrium or dominated actions are announced, preplay communication is non credible and players ignore it. But, what if I make an announcement such that if you believe me and respond optimally, then it is in my own interest to stick to my word? Farell (1987) argues that in this case my announcement should be credible. Thus, in our game, when $\bar{q}=11$, participants could credibly announce during the preopening their intention to play $(S 2, B 2)$ in the call auction. This suggests that the presence of the preopening period should enhance coordination on the Pareto dominant Nash equilibrium and leads to the following hypothesis.

Hypothesis 5 When $\bar{q}=11$, with a nonbinding preopening period, sellers will tend to play $S 2$ at $t=0$ and at $t=1$, and buyers will respond to this by playing $B 2$ at $t=1$. The symmetric argument applies to the other side of the market.

Yet, Aumann (1990) offers a counterargument to this conjecture. Suppose I announce I will play $S 2$ and the buyer believes me. Then he responds with $B 2$. Now, I prefer him to choose this response irrespective of whether I really want to play $B 2$ or $B 1$. Thus, argues Aumann (1990), my announcement is not self-enforcing. This suggests it may not be credible and preplay communication with nonbinding orders may not enhance coordination on the Pareto dominant equilibrium. This is in line with Clark et al (2001), who consider a game where the Aumann critique applies. They find that cooperation is played $42 \%$ of the time but announced $81 \%$ of the time. In our game, as in theirs, parameters are such that the Aumann's critique applies.

\subsubsection{History}

To design their strategies, players need to form beliefs about the moves of their opponents. Such beliefs are likely to be shaped by the observation of past actions, thus generating history dependence. In the market with a nonbinding preopening period, low initial gains from trades can induce pessimistic beliefs. In that market, according to Hypothesis 2 , even when $\bar{q}=9$, agents will play $S 2$ or $B 2$ at $t=0$, hoping to manipulate their opponent, and then they will play $S 1$ and $B 1$ at $t=1$. Such actions risk undermining the credibility of preplay communication. In that case, even when the maximum amount traded goes to 11, players might not respond positively to cooperative messages ( $S 2$ or $B 2$ ) sent at $t=0$. Accordingly, we posit the following hypothesis: 
Hypothesis 6 Cooperative messages sent during the nonbinding preopening with $\bar{q}=11$ will elicit less positive responses when participants have previously played with $\bar{q}=9$.

\section{Experimental design}

To test these hypotheses, we conducted a market experiment at the Toulouse University laboratory. We studied participants behavior in three treatments: $i$ ) a pure call market without preopening, ii) a call auction preceded by a nonbinding preopening period, iii) a call auction preceded by binding preopening orders. The experiment was programmed and conducted with the software zTree (Fischbacher, 2007). The participants were seated in front of computers separated by dividers and we enforced a ban on verbal communication. The experiments involved 156 students from three different master in finance programs at Toulouse University. There were 12 cohorts. The number of participants per cohort varied between 8 and 20. Each cohort played only in one market environment.

In each cohort, participants played the market game 15 times. Each time they were randomly and blindly matched with an opponent, and this was orally announced to all by the experimenter so that it was common knowledge. Anonymity and random matching ensured that each time participants would behave as in a one-shot game. Relying on anonymous computerized interaction with a prespecified set of messages, we avoid the confounding effects associated with face to face interaction noted by Roth (1995). ${ }^{11}$

At each round, the computer collected all the choices and randomly matched one seller and one buyer within a given cohort. Payoffs were determined according to the normal form game table given above. At the end of each replication, each participant was informed of his or her trading gains. Subjects were not told with whom they were matched, but they were informed of the actions of their opponent. The subjects were not informed of the outcomes of the matches in which they did not participate. When there was a preopening period, the same two players were matched both for the preopening period and the subsequent call market.

To study the effect of history on behavior, we exposed participants to variations in $\bar{q}$. In the first ten cohorts, half the participants first played 5 rounds with $\bar{q}=11$, followed by 5 rounds with $\bar{q}=9$, and then 5 more rounds with $\bar{q}=11$. For the other participants in these first ten cohorts, the sequencing was reversed: they first played 5 rounds with $\bar{q}=9$, then 5 rounds with $\bar{q}=11$, and finally 5 rounds with $\bar{q}=9$. We did not tell the participants what the exact process of $\bar{q}$ would be. We just informed them that $\bar{q}$ would vary between 9 and 11 across rounds and participants. When $\bar{q}$ changed, we clearly warned the participants of this alteration in the parameters via screen

\footnotetext{
${ }^{11}$ preplay communication in our game takes the form of rather terse, pre-set, messages, such as "B1" or " $S 2$ ". This differs from the rich, free-form messages studied by Charness and Dufwenberg (2006).
} 
messages, to avoid any confusion.

We also wanted to disentangle the pure effect of market structure from its effect combined with history. To do so, we also ran the experimental market keeping $\bar{q}$ constant. Since, as will be clear below, experimental outcomes are quite straightforward when $\bar{q}=9$ and also in the pure call auction, we ran these control experiments only for $\bar{q}=11$ and for the market with a binding preopening and that with a nonbinding one. This control treatment enables us to check that, as predicted by Hypothesis 6, there is a difference between the first five rounds and the next ones for the cohorts which faced changes in $\bar{q}$, not for the other ones. It also enables us to examine the difference between the binding and nonbinding preopening cases in absence of changes in $\bar{q}$, and thus to test directly Hypotheses 2,3,4 and 5.

The composition of the cohorts and the treatments are summarized in Table 1. We first ran the experiment with 7 cohorts, in the context of our original design, which involved the three market structure and changes in $\bar{q}$. Then, to check the robustness of the difference between the binding and nonbinding preopenings, we replicated the experiment for these two market structures (keeping the changes in $\bar{q}$ as in the first 7 cohorts). The results obtained for all these cohorts are qualitatively similar, hence we report results based on pooled data. Finally, to control for the role of variations in market conditions, we studied the benchmark case where there are no changes in $\bar{q}$.

In each cohort, we first explained the game to the participants and gave them an instruction sheet. An example of the instructions, for the pure call auction market, is given in Appendix. We answered questions to ensure the participants understood the mechanics of the market. At the same time we carefully avoided giving them any hints as to how they should play. This presentation phase lasted around thirty minutes. Then the market game took place. First, each cohort went through 6 practice rounds. Then, the 15 "real" rounds took place. At each round the participants had 3 minutes to place their orders. In the pure call auction case, this meant they had 3 minutes to choose which order to place in the call auction. When there was a preopening, participants had 90 seconds to choose the orders they would place during the preopening and then 90 seconds to place orders in the call auction. We chose this design to ensure that the total decision time would be the same across all treatments. This way, if superior performance was obtained in markets with a preopening period, it could not be due to longer decision time. Overall the market game lasted around one hour and a half for each cohort. The participants were also told that, after the 15 sessions, they would receive a payment in euros equal to their total number of points divided by 15. The average payment was $€ 18$, the minimum was 15 and the maximum 21 . 


\section{Results}

\subsection{Executed orders}

Pooling buyers and sellers, Table 2 presents the orders that were taken into account to generate trades. ${ }^{12}$ To document the evolution of behavior, the table breaks down the results obtained during the first five periods, the following five periods, and the last five periods.

Panels A and B depict what happens when participants faced varying parameter values. Panels A and B correspond to treatments that begin with $\bar{q}=11$ and $\bar{q}=9$, respectively. Panels A2, B1 and B3 correspond to the periods during which $\bar{q}=9$. As stated below, in that case, participants easily discover the dominant strategy equilibrium, consistent with Hypothesis 1.

Finding 1 When $\bar{q}=9$, the most frequent actions are $B 1$ and $S 1$, with frequencies ranging from $78 \%$ in the pure call auction during the first five rounds, to $95.8 \%$ in the market with a binding preopening period during the last five rounds.

Panels A1, A3 and B2 present the findings for $\bar{q}=11$. The most frequent actions are $B 2$ and $S 2$, corresponding to the Pareto dominant equilibrium, but there are large variations across market structures and through time. When the participants play with $\bar{q}=11$ during the first five rounds, the difference between the three market structures is relatively small, as $B 2$ or $S 2$ is played $76 \%$ of the time in the pure call auction, $60.8 \%$ when the preopening is nonbinding, and $73,3 \%$ when it is binding (the difference between the pure call auction and the auction with a binding preopening is not statistically significant). But, later in the experiment, the performances of the three market structures diverge.

Consider the case where participants play with $\bar{q}=11$ after having been exposed to $\bar{q}=9$ :

- In the pure call auction, the proportion of $B 2$ or $S 2$ is equal to $58 \%$ in rounds 6 to 10 (see Panel B2), and 54\% in rounds 11 to 15 (see Panel A3). This is statistically different, at the $5 \%$ level, from the frequency observed during the first five rounds $(76 \%)$.

- In the market where the preopening is nonbinding, the proportion of $B 2$ or $S 2$ is $50.8 \%$ in rounds 6 to 10 (see Panel B2), which is statistically different, at the $5 \%$ level, from the frequency observed during the first five rounds. The proportion of $B 2$ or $S 2$ is $56.7 \%$ in rounds 11 to 15 (see Panel A3). This is lower than, but not statistically different from, the frequency observed in the first five rounds $(60.8 \%)$.

\footnotetext{
${ }^{12}$ In the pure call auction these are simply the limit orders placed by the agents. In the market with nonbinding preopening orders, these are the orders placed at time 1 in the call auction. In the market with binding preopening orders, these are the orders placed by the participants, either at time 0 during the preopening or at time 1 during the call auction.
} 
- With a binding preopening, the percentage of $B 2$ or $S 2$ is $87.5 \%$ in rounds 6 to 10 (see Panel B2), and $90.8 \%$ in rounds 11 to 15 (see Panel A3), which is even higher than the frequency observed during the first five rounds $(73.3 \%)$.

These findings are summarized below:

Finding 2 When $\bar{q}=11$, if players have not previously been exposed to $\bar{q}=9$, the frequency of $B 2$ and $S 2$ is relatively high. If the players have previously been exposed to $\bar{q}=9$, then the frequency of $B 2$ or $S 2$ is relatively low in the pure call auction and in the market with a binding preopening period. But it is quite high in the market with a binding preopening period.

Thus the nonbinding preopening does not increase the play of $B 2$ and $S 2$. This contradicts Hypothesis 5, and is more in line with the Aumann critique than with the argument of Farell. In contrast, the preopening facilitates coordination on high liquidity and gains from trade when it involves binding orders. This is consistent with participants reaching the unique trembling hand perfect equilibrium outcome, in line with Hypothesis 2.

Panel $\mathrm{C}$ of Table 2 presents the results obtained in the benchmark case where $\bar{q}$ is constant and equal to 11. Similarly to Panels A and B, we see that the market with a binding preopening period outperforms the market with a nonbinding period. But, in contrast with Panels A and B, we observe no difference between the first five rounds and the next five rounds. When the preopening period is nonbinding, the frequency of $B 2$ or $S 2$ is $43 \%$ during the first five rounds and $45 \%$ during the next five rounds. When the preopening period is binding, the frequency of $B 2$ or $S 2$ is $77 \%$ during the first five rounds and $76 \%$ during the next five rounds. This confirms that the decline of the performance of the nonbinding preopening observed in panels B2 and A3 is due to the reaction of participants to previous bitter experiences. We also observe, in Panel C3 of Table 2 that the market with a nonbinding preopening performs poorly during the last five rounds. This may reflect that participants were getting bored after playing more than 10 replications of the same game. Their behavior at this point contrasts with persistence of the coordination on the Pareto dominant equilibrium in the market with a binding preopening period, which offers yet another illustration of the efficiency of the latter market structure.

\subsection{Mismatches}

The results are in Table 3 . When $\bar{q}=11$, the frequency of $(S 1, B 2)$ or $(S 2, B 1)$ is statistically significantly larger, at the $5 \%$ level, in the pure call auction than in the market with a nonbinding preopening. And this frequency is statistically significantly lower with a binding preopening than with a nonbinding one. These results, which are consistent with Hypothesis 3, are summarized below: 
Finding 3 Mismatches such as $(S 1, B 2)$ or $(S 2, B 1)$ are rather frequent in the pure call auction. In contrast the presence of a preopening period reduces the occurrence of mismatches, especially in the market with a binding preopening.

Table 3, also shows that mismatches are more frequent when $\bar{q}=11$ than when $\bar{q}=9$. This is natural since there are multiple equilibria in the former case and not in the latter (when $\bar{q}=$ 9 , whether the preopening period is binding or not does not statistically affect the frequency of mismatches).

\subsection{Manipulation and coordination during the preopening period}

\subsubsection{Orders placed during the preopening and the opening}

Table 4 documents the evolution of the orders placed by the same player at $t=0$ and then $t=1$. Panels A to D present the evidence for the treatment where participants faced changes in $\bar{q}$. Panels $\mathrm{E}$ and $\mathrm{F}$ present the evidence for the control treatment where $\bar{q}$ was kept constant at 11 .

As can be seen in panel $\mathrm{A}$, in the nonbinding preopening period when $\bar{q}=9$, the majority of the orders (63.6\%) is of type $B 2$ or $S 2$. But after sending such "cooperative messages," the agents shift to the opposite strategy at $t=1$ and play $B 1$ or $S 192.6 \%$ of the time. These results, which are consistent with Hypothesis 4, are summarized below:

Finding 4 When $\bar{q}=9$, in the nonbinding preopening, orders are manipulative: players "announce cooperation" at $t=0$ but "play defection" at $t=1$.

In contrast, Panel B of Table 4 shows that in the binding preopening period when $\bar{q}=9$, the vast majority of the orders $(77.8 \%)$ is of type $B 0$ or $S 0$ at $t=0$. Since playing $B 2$ or $S 2$ during the preopening would be binding, players cannot try to manipulate their opponent. So they often choose to wait. After these non-committing orders, in the vast majority of cases $(93.2 \%)$, players follow the dominant strategy $B 1$ or $S 1$ at $t=1$.

When $\bar{q}=11$, as shown in Panels $\mathrm{C}$ and $\mathrm{E}$ of Table 4, in the nonbinding preopening period the majority of the orders is of type $B 2$ or $S 2$ ( $80.0 \%$ in Panel C and $74.3 \%$ in Panel E). These orders tend to be informative since orders placed at $t=1$ are related to those placed at $t=0$. However time 0 orders are not always reliable indications of subsequent play, since, at $t=1$, agents play $B 2$ or $S 2$ only $60.1 \%$ of the time in Panel C and $43.5 \%$ in Panel E.

Panel $\mathrm{D}$ and $\mathrm{F}$ show that, in the binding preopening period when $\bar{q}=11$, agents often choose to wait ( $44.4 \%$ of the cases in Panel D and $45.3 \%$ in Panel F). This is likely to reflect uncertainty about the play of their opponent. Yet, during the binding preopening, a significant fraction of the orders placed at $t=0$ is of type $B 2$ or $S 2$ (52.5\% in Panel D and $46 \%$ in Panel F). Such orders 
commit the players to $B 2$ or $S 2$ at $t=1$. They are likely to reflect coordination by the agents on the trembling hand perfect equilibrium, consistent with Hypothesis 2.

\subsubsection{The response to preopening orders}

Table 5 documents how the players responded at time 1 to the order posted by their opponent during the preopening. Again Panels A to D present the evidence for the treatment where participants faced changes in $\bar{q}$, while Panels E and F present the evidence for the control treatment where $\bar{q}$ was kept constant at 11 .

When $\bar{q}=9$, as shown in Panel A, in the market with a nonbinding preopening period, agents' actions at $t=1$ are not affected by their opponent's move at $t=0$. In the vast majority of cases, the agents play $S 1$ or $B 1$ at $t=1$. The play of $B 2$ or $S 2$ at $t=0$ by their opponent does not induce them to play $B 2$ or $S 2$ at $t=1$. This result, which is consistent with Hypothesis 4 , is stated below:

Finding 5 In the nonbinding preopening, when $\bar{q}=9$, attempts to manipulate are frequent but ineffective.

Panel B presents the results obtained in the market with a binding preopening when $\bar{q}=9$. This panel reports the choices made at time 1 by participants who chose to wait at time 0 (the others are committed by their time 0 move and therefore have no opportunity to respond.) In that market also, the vast majority of agents respond $B 1$ or $S 1$ at $t=1$, whatever the move of their opponent at time 0 . Thus, participants play dominant strategies, consistent with Hypothesis 1 .

When $\bar{q}=11$, as shown in Panels $\mathrm{C}$ and $\mathrm{E}$ of Table 5, in the market with a nonbinding preopening period, agents tend to be responsive to the order placed by their opponent at time 0 . When the preopening order of their opponent was $B 1$ or $S 1$, they play $B 1$ or $S 185.4 \%$ of the time in Panel C and $82.1 \%$ in Panel E. When the preopening order of their opponent was $B 2$ or $S 2$, they play $B 2$ or $S 262.8 \%$ of the time in Panel C and $46.6 \%$ in Panel E. Thus, the response to the play of $B 2$ or $S 2$ during the preopening tends to be weak. This suggests participants don't place a lot of trust in the preopening orders.

Panels $\mathrm{D}$ and $\mathrm{F}$ present, for the binding preopening and $\bar{q}=11$, the choices made at time 1 by participants who chose to wait at time 0 . The response to $B 1$ or $S 1$ (100\% of $S 1$ or $B 1$ in Panel D and $81.8 \%$ in Panel F) and the response to $B 2$ or $S 2(81.9 \%$ of $S 2$ or $B 2$ in Panel D and $91.3 \%$ in Panel F) show that players best respond. Since players rarely choose to play B1 or S1 at date $t=0$, this result again illustrates that the binding preopening is effective at fostering coordination on the Pareto dominant outcome, consistent with Hypothesis 2. 


\subsection{History dependence}

Tables 6, 7 and 8 show the evolution of the response of the players to the order posted by their opponent during the preopening. ${ }^{13}$ Table 6 documents the case where the maximum trade was 11 during the first five rounds, changed to 9 during the next five rounds, and finally reverted to 11 during the last 5 rounds. Table 7 presents the evidence for the other possible sequence, for which the maximum trade was 9 during the first five rounds, 11 during the next five rounds, and 9 during the last 5 rounds. The first type of sequence corresponds to the case where the agents started interacting in rather good market conditions $(\bar{q}=11)$, where high gains from trade could be achieved in equilibrium. In contrast, the second type of sequence started with tough market conditions $(\bar{q}=9)$, where equilibrium generated low gains from trade. Finally, Table 8 presents the evidence for the treatment where $\bar{q}$ was constant and equal to 11 during the 15 rounds.

\subsubsection{The market with a nonbinding preopening period}

Panel A of Table 6 shows that during the first five rounds, when the maximum trade is 11, so that there are two Nash equilibria $(S 1, B 1)$ and $(S 2, B 2)$, the messages sent during the nonbinding preopening period influence actions at $t=1$. When their opponent played $B 1$ or $S 1$ during the preopening period, agents play $B 1$ or $S 177.8 \%$ of the time. And when their opponent played $B 2$ or $S 2$ during the preopening period, agents play $B 2$ or $S 269.6 \%$ of the time. ${ }^{14}$

This contrasts with Panel B of Table 7, which shows the responses observed during rounds 5 to 10 , when the maximum trade is currently 11 , but the agents have experienced $\bar{q}=9$ during the first 5 rounds. In that case the play of $B 1$ or $S 1$ during the preopening does elicit the response $B 1$ or $S 1$ at $t=1$. But when their opponent played $B 2$ or $S 2$ during the preopening, agents respond with $B 2$ or $S 2$ at $t=1$ only $57.7 \%$ of the time. A Chi-square test reveals that this is statistically different, at the $5 \%$ level, from the frequency observed during the first five rounds, i.e., $69.6 \%$. During the first five rounds, these agents have observed manipulative announces of $B 2$ or $S 2$ at $t=0$, followed by the play of $B 1$ or $S 1$ at $t=1$. Thus they have lost faith in the credibility of "cooperative messages" sent during the preopening. Hence, consistent with Hypothesis 6, the play of $B 2$ or $S 2$ during the preopening period often fails to elicit a positive $B 2$ or $S 2$ response.

A similar but less strong phenomenon is documented in Panel $\mathrm{C}$ of Table 6, which shows the responses observed during rounds 11 to 15 , when the maximum trade is currently 11 , but was 9 during the previous market phase. These agents have experienced fruitful cooperation during the first five rounds of the game, and then manipulative messages during the next five rounds.

\footnotetext{
${ }^{13}$ Again, for the binding preopening case, we consider the time 1 choices of participants who played $B 0$ or $S 0$ at time 0 . The others are committed by their time 0 moves, and therefore cannot respond to preopening orders.

${ }^{14} \mathrm{~A} \mathrm{Chi-square} \mathrm{test} \mathrm{reveals} \mathrm{that} \mathrm{the} \mathrm{frequency} \mathrm{of} B 2$ or $S 2$ is statistically significantly different (at the $5 \%$ level) in the two cases.
} 
Correspondingly, on observing that their opponent played $B 2$ or $S 2$ during the preopening period, they respond $B 2$ or $S 261.6 \%$ of the time. This is below the strong positive response rate which prevailed for those agents during the first five periods $(69.6 \%)$ but this difference is significant at the $10 \%$ level only. And it is not significantly above the weak response rate $(57.7 \%)$ prevailing during rounds 6 to 10 , for agents who had started the games with five rounds of tough market conditions, with $\bar{q}=9$.

Table 8 presents the evidence for the control treatment where $\bar{q}$ is constant and equal to 11 . As in the other cases, agents tend to respond $B 1$ to $S 1$ and $S 1$ to $B 1$. The extent to which they respond positively to $B 2$ or $S 2$ is relatively limited. But, in contrast with the evidence in Tables 6 and 7 , there is no decline in the frequency of positive responses from the first five periods the next five periods. Quite to the contrary there is an increase: During the first five periods, after observing $B 2$ or $S 2$, participants respond $S 2$ or $B 252.1 \%$ of the time. During the next five periods, the frequency of such positive responses rises non significantly to $56.6 \%$. It must be noted, however, that there is an eventual decline in the frequency of positive responses, during the last five rounds.

These results, which are consistent with Hypothesis 6, are summarized below:

Finding 6 In the nonbinding preopening, when $\bar{q}=11$, the positive response elicited by the play of $B 2$ or $S 2$ at time 0 is weaker when participants have previously been exposed to $\bar{q}=9$ than when they have not.

\subsubsection{The market with a binding preopening period}

Interestingly, the evolution of play is quite different in the market with a binding preopening period. There, when $\bar{q}=11$, the frequency of positive responses to $B 2$ or $S 2$ during the preopening is $70.4 \%$ during the first five rounds (see Table 6 Panel A), $93.8 \%$ during the next five rounds (see Table 7, Panel B) and 80\% during the last five rounds (see Table 6, Panel C). These results, which are in line with Hypothesis 2, are summarized below:

Finding 7 When the preopening is binding and $\bar{q}=11$, coordination on the Pareto dominant equilibrium is robust to tough market conditions, as the frequency of B2 or S2 remains high after agents have experienced markets with $\bar{q}=9$.

The difference between the two types of preopening periods directly manifests itself only when $\bar{q}=11$. When $\bar{q}=9,(S 1, B 1)$ is a dominant strategy equilibrium, and this equilibrium arises irrespective of the market structure. But the behavior of the participants during the preopening when $\bar{q}=9$ has indirect effects, since it influences their beliefs and consequently their actions at later stages in the game. Table 8 shows that the frequency of positive responses to $B 2$ or $S 2$ is also very large in the control treatment where $\bar{q}$ is constant. 


\section{Conclusion}

We study experimentally the performance of three trading mechanisms: $i$ ) a pure call auction, $i i$ ) a nonbinding preopening period followed by a call auction, and $\mathrm{iii}$ ) a binding preopening period followed by a call auction. We investigate whether the preopening period facilitates coordination on the Pareto dominant equilibrium and how its role is affected by the evolution of market conditions.

We find that, with a nonbinding preopening period, agents try to manipulate their opponents by sending noncredible, falsely "cooperative," messages. While these messages don't fool traders, they reduce the credibility of preopening orders. Thus, in the market with a nonbinding preopening period, gains from trade are relatively low. In contrast, by construction, the binding preopening period is immune to manipulation. It enables traders to achieve high coordination and gains from trade.

While our analysis suggests that the poor performance of the nonbinding preopening is due to agents learning to distrust announces, we don't formally model learning or beliefs formation. It would be interesting, in future research to analyze such beliefs dynamics. To conduct this analysis, one could rely on the models of learning dynamics in coordination games offered by Crawford and Haller (1990) and Crawford (1995).

Our experiment offers a warning to market designers. Purely nonbinding preopening mechanisms can be destabilized by manipulative traders. In contexts where gains from trade are limited, traders can be tempted to use preplay communication in an opportunistic way. This could have a long-lasting negative effect on the credibility and usefulness of the preopening period. But market organizers can strive to design effective communication mechanisms to cope with this problem. Admittedly, the fully binding preopening mechanism considered in the present paper is a rather coarse solution. In practice, market designers might find it more effective to rely on less simplistic methods. For example, in several markets (e.g. the German stock market Xetra), the actual time of the opening is random. Thus, preopening orders end up being firm orders with some probability, when the market opens before the order could be cancelled. Other methods are to constrain the ability of the traders to revise their orders. For example, in some markets, orders can be cancelled only if they are replaced with new orders providing more liquidity to the market. Or market designers can impose a fee on cancellations taking place during the preopening period.

Our results should nevertheless be taken with a grain of salt. Our trading game is highly stylized. Other important effects are likely to be at play in real markets and affect the usefulness of preopening mechanisms. In particular, in our experiment, while there is strategic uncertainty (about the actions of the others), there is no uncertainty about parameters of the game, such as the maximum level of trade or the value of the asset. Introducing such uncertainty would enrich the analysis and the potential role of the preopening period. We leave these issues for further research. 


\section{References}

Admati, Anat R., and Paul Pfleiderer. 1988. "A Theory of Intraday Patterns: Volume and Price Variability." The Review of Financial Studies, 1(1): 3-40.

Aumann, Robert. 1990. "Nash Equilibria are Not Self-Enforcing." In Economic DecisionMaking: Games, Econometrics and Optimisation, ed. Gabszewicz, Jean Jaskold, JeanFrançois Richard, and Laurence A. Wolsey, 201-206. Amsterdam: Elsevier.

Aumann, Robert, Michael Maschler, and Richard Stearns. 1968. "Repeated Games of Incomplete Information: An Approach to the Non-Zero-Sum Case." Mathematica, 117-216.

Battalio, Raymond, Larry Samuelson, and John Van Huyck. 2001. "Optimization Incentives and Coordination Failures in Laboratory Stag-Hunt Games.” Econometrica, 69(3): 749-764.

Biais, Bruno, Pierre Hillion, and Chester Spatt. 1999. "Price Discovery and Learning during the Preopening Period in the Paris Bourse.” The Journal of Political Economy, 107(6): 12181248.

Blume, Andreas, and Andreas Ortmann. 2007. "The effects of costless preplay communication: Experimental evidence from games with Pareto-ranked equilibria." The Journal of Economic Theory, 132(1): 274-290.

Charness, Gary. 2000. “Self-Serving Cheap Talk: A Test of Aumann's Conjecture.” Games and Economic Behavior, 33(2): 177-194.

Charness, Gary, and Martin Duwfenberg. 2006. "Promises and partnerships.” Econometrica, 74(6): 1579-1601.

Clark, Kenneth, Steven Kay and Martin Sefton. 2001. "When are Nash equilibria selfenforcing?" International Journal of Game Theory, 29(4): 495-515.

Cooper, Russell, Douglas V. DeJong, Robert Forsythe, and Thomas W. Ross. 1992, "Communication in Coordination Games." The Quarterly Journal of Economics, 107(2): 739-773.

Crawford, Vincent. 1998. "A Survey of Experiments on Communication via Cheap Talk." Journal of Economic Theory, 78(2): 286-298.

Crawford, Vincent, and Hans Haller. 1990. "Learning how to cooperate: Optimal play in repeated coordination games ." Econometrica, 58(3): 571-595. 
Crawford, Vincent. 1995. "Adaptive dynamics in coordination games." Econometrica, 63(1): 103-143.

Davies, Ryan J. 2003. “The Toronto Stock Exchange preopening session.” Journal of Financial Markets, 6(4): 491-516.

Deutsche Börse. 2004. "Market model: equities." http: / / deut sche-boerse.com

Dow, James. 2004. “Is Liquidity Self-Fulfilling?” Journal of Business, 77(4): 895-908.

Farrell, Joseph. 1987. "Cheap Talk, Coordination and Entry." RAND Journal of Economics, 18(1): 34-39.

Farrell, Joseph, and Matthew Rabin. 1996. "Cheap Talk.” Journal of Economic Perspectives, 10(3): 103-118.

Fischbacher, Urs. 2007. "z-Tree: Zurich Toolbox for Ready-made Economic Experiments." Experimental Economics, 10(2): 171-178.

Forsythe, Robert, Russell Lundholm, and Thomas Rietz. 1999. "Cheap Talk, Fraud, and Adverse Selection in Financial Markets: Some Experimental Evidence." The Review of Financial Studies, 12(3): 481-518.

Pagano, Marco. 1989. "Trading Volume and Asset Liquidity." The Quarterly Journal of Economics, 104(2): 255-274.

Roth, Alvin E. 1995. "Bargaining experiments." In Handbook of Experimental Economics, ed. John H. Kagel and Alvin E. Roth, 253-348, Princeton University Press, Princeton, New Jersey.

Schmidt, David, Robert Shupp, James M. Walker, and Elinor Ostrom. 2003. "Playing safe in coordination games: the roles of risk dominance, payoff dominance, and history of play." Games and Economic Behavior, 42(2): 281-299.

Van Huyck, John, Raymond Battalio, and Richard Beil. 1990. "Tacit coordination games, strategic uncertainty, and coordination failure.” The American Economic Review, 80(1): 234-248.

Selten, Reinhardt. 1975. "A reexamination of the perfectness concept for equilibrium points in extensive games." International Journal of Game Theory, 4(1): 25-55. 


\section{Appendix: Instructions to participants, in the pure call market (without a preopening)}

In this market you can place buy or sell limit orders in a uniform price call auction. If you play astutely you can make some good money. Buyers start with no share. Each share they buy is worth 4 points for them. Sellers start each trading round with a new endowment of 9 or 11 shares. For them each share is worth 0 point. All traders know how many shares the seller has. There is no link between periods. Cash or shares are not carried over from one period to the next. At the end of each round we compute profits. For buyers this is: number shares bought $\times(4-$ price $)$. For sellers this is: number of shares sold $\times$ price. At the end of the experiment you receive in $€$ your profit divided by 15 . Only profits matter (as opposed to total wealth) and buyers are assumed to have enough cash to pay for the shares they want to acquire.

At each trading round, each buyer is randomly \& anonymously matched with one seller. Prices $\&$ trades are set in a uniform price call auction, crossing the buy \& sell orders. For each pair, the supply curve of seller $\&$ the demand function of the buyer are crossed in a uniform price call auction, setting the price $\&$ volume for this round $\&$ this pair of traders.

At each round, each seller chooses between 3 schedules of limit orders:

- S0: Don't sell at any price,

- S1: One order to sell 8 shares if price not below 2; another order to sell $X$ additional shares if price not below 3 ,

- S2: One order to sell 8 shares if price not below 1; another order to sell additional $X$ shares if price not below 2,

and each buyer chooses between 3 schedules of limit orders.

- B0: Don’t want to buy at any price,

- B1: One limit order to buy 8 shares if the price is not above 2; another limit order to buy $X$ additional shares if the price is not above 1 ,

- B2: One limit order to buy 8 shares if the price is not above 3; another limit order to buy $X$ additional shares if the price is not above 2 .

When the maximum trade is 11 , then $X=3$. When the maximum trade is $9, X=1$.

When the maximum trade is 11 shares, the possible trades and profits are the following:

- B0 or S0: no trade, profits $=0$.

- B2 \& S2: price $=2$, volume $=11$. Profit of buyer $=$ profit of seller $=22$.

- B1 \& S1: price $=2$, volume $=8$. Profit of buyer $=$ profit of seller $=16$.

- B1 \& S2: price $=1.5$, volume $=8$. Profit of buyer $=20$, profit of seller $=12$. 
- B2 \& S1: price $=2.5$, volume $=8$. Profit of buyer $=12$, profit of seller $=20$.

When the maximum trade is 9 shares, the possible trades and profits are the following:

- B0 or S0: no trade, profits $=0$.

- B2 \& S2: price $=2$, volume $=9$. Profit of buyer $=$ profit of seller $=18$.

- B1 \& S1: price $=2$, volume $=8$. Profit of buyer $=$ profit of seller $=16$.

- B1 \& S2: price $=1.5$, volume $=8$. Profit of buyer $=20$, profit of seller $=12$.

- $\mathrm{B} 2 \& \mathrm{~S} 1$ : price $=2.5$, volume $=8$. Profit of buyer $=12$, profit of seller $=20$.

We will start with 6 warm up rounds, so that you can familiarize with the game (no points will be earned during these 6 rounds). During these 6 rounds you'll sometimes be a buyer and sometimes a seller. Then, there will be 15 trading rounds, during which you'll earn $€$. The number of $€$ you will earn will be your total accumulated profit/15. At the beginning of the 15 rounds, you will be assigned a role: buyer or seller, which you'll keep throughout the game. In some rounds the maximum trade will be 9 shares, in others max number of shares traded will be 11. At each round, before players choose orders, the maximum trade will be announced to all. 
Table 1: Cohorts and participants in the experiment

\begin{tabular}{|c|c|c|c|}
\hline Cohort number & Market structure & $\bar{q}$ & Number of participants \\
\hline 1 & Without preopening & 9 or 11 & 12 \\
2 & nonbinding preopening & 9 or 11 & 12 \\
3 & nonbinding preopening & 9 or 11 & 12 \\
4 & Without preopening & 9 or 11 & 8 \\
5 & nonbinding preopening & 9 or 11 & 8 \\
6 & Binding preopening & 9 or 11 & 8 \\
7 & Binding preopening & 9 or 11 & 8 \\
8 & Binding preopening & 9 or 11 & 16 \\
9 & nonbinding preopening & 9 or 11 & 16 \\
10 & Binding preopening & 9 or 11 & 16 \\
11 & nonbinding preopening & 11 & 20 \\
12 & Binding preopening & 11 & 20 \\
\hline
\end{tabular}


Table 2: Outcomes of the game

Panel A1: Rounds 1 to $5, \bar{q}=11$

\begin{tabular}{|c|c|c|c|}
\hline Order type & $\begin{array}{c}\text { Pure Call Auction } \\
\text { Without preopening }\end{array}$ & $\begin{array}{c}\text { Call Auction following } \\
\text { nonbinding Preopening }\end{array}$ & $\begin{array}{c}\text { Call Auction following } \\
\text { Binding Preopening }\end{array}$ \\
\hline$B 0$ or $S 0$ & - & - & - \\
$B 1$ or $S 1$ & $24.0 \%$ & $39.2 \%$ & $26.7 \%$ \\
$B 2$ or $S 2$ & $76.0 \%$ & $60.8 \%$ & $73.3 \%$ \\
\hline
\end{tabular}

Panel A2: Rounds 6 to $10, \bar{q}=9$

\begin{tabular}{|c|c|c|c|}
\hline Order type & $\begin{array}{c}\text { Pure Call Auction } \\
\text { Without preopening }\end{array}$ & $\begin{array}{c}\text { Call Auction following } \\
\text { nonbinding Preopening }\end{array}$ & $\begin{array}{c}\text { Call Auction following } \\
\text { Binding Preopening }\end{array}$ \\
\hline$B 0$ or $S 0$ & - & - & $0.8 \%$ \\
$B 1$ or $S 1$ & $84.0 \%$ & $90.8 \%$ & $89.2 \%$ \\
$B 2$ or $S 2$ & $16.0 \%$ & $9.2 \%$ & $10.0 \%$ \\
\hline
\end{tabular}

Panel A3: Rounds 11 to $15, \bar{q}=11$

\begin{tabular}{|c|c|c|c|}
\hline Order type & $\begin{array}{c}\text { Pure Call Auction } \\
\text { Without preopening }\end{array}$ & $\begin{array}{c}\text { Call Auction following } \\
\text { nonbinding Preopening }\end{array}$ & $\begin{array}{c}\text { Call Auction following } \\
\text { Binding Preopening }\end{array}$ \\
\hline$B 0$ or $S 0$ & - & - & $0.8 \%$ \\
$B 1$ or $S 1$ & $46.0 \%$ & $43.3 \%$ & $8.3 \%$ \\
$B 2$ or $S 2$ & $54.0 \%$ & $56.7 \%$ & $90.8 \%$ \\
\hline
\end{tabular}

Panel B1: Rounds 1 to $5, \bar{q}=9$

\begin{tabular}{|c|c|c|c|}
\hline Order type & $\begin{array}{c}\text { Pure Call Auction } \\
\text { Without preopening }\end{array}$ & $\begin{array}{c}\text { Call Auction following } \\
\text { nonbinding Preopening }\end{array}$ & $\begin{array}{c}\text { Call Auction following } \\
\text { Binding Preopening }\end{array}$ \\
\hline$B 0$ or $S 0$ & - & - & $0.8 \%$ \\
$B 1$ or $S 1$ & $78.0 \%$ & $88.3 \%$ & $79.2 \%$ \\
$B 2$ or $S 2$ & $22.0 \%$ & $11.7 \%$ & $20.0 \%$ \\
\hline
\end{tabular}

Panel B2: Rounds 6 to $10, \bar{q}=11$

\begin{tabular}{|c|c|c|c|}
\hline Order type & $\begin{array}{c}\text { Pure Call Auction } \\
\text { Without preopening }\end{array}$ & $\begin{array}{c}\text { Call Auction following } \\
\text { nonbinding Preopening }\end{array}$ & $\begin{array}{c}\text { Call Auction following } \\
\text { Binding Preopening }\end{array}$ \\
\hline$B 0$ or $S 0$ & - & - & $0.8 \%$ \\
$B 1$ or $S 1$ & $42.0 \%$ & $49.2 \%$ & $11.7 \%$ \\
$B 2$ or $S 2$ & $58.0 \%$ & $50.8 \%$ & $87.5 \%$ \\
\hline
\end{tabular}

Panel B3: Rounds 11 to $15, \bar{q}=9$

\begin{tabular}{|c|c|c|c|}
\hline Order type & $\begin{array}{c}\text { Pure Call Auction } \\
\text { Without preopening }\end{array}$ & $\begin{array}{c}\text { Call Auction following } \\
\text { nonbinding Preopening }\end{array}$ & $\begin{array}{c}\text { Call Auction following } \\
\text { Binding Preopening }\end{array}$ \\
\hline$B 0$ or $S 0$ & $2.0 \%$ & - & $0.8 \%$ \\
$B 1$ or $S 1$ & $84.0 \%$ & $93.3 \%$ & $95.8 \%$ \\
$B 2$ or $S 2$ & $14.0 \%$ & $6.7 \%$ & $3.3 \%$ \\
\hline
\end{tabular}


Table 2: Outcomes of the game (cont)

Panel C1: Benchmark case, rounds 1 to $5, \bar{q}=11$

\begin{tabular}{|c|c|c|}
\hline Order type & $\begin{array}{c}\text { Call Auction following } \\
\text { nonbinding Preopening }\end{array}$ & $\begin{array}{c}\text { Call Auction following } \\
\text { Binding Preopening }\end{array}$ \\
\hline$B 0$ or $S 0$ & $3.0 \%$ & - \\
$B 1$ or $S 1$ & $54.0 \%$ & $23.0 \%$ \\
$B 2$ or $S 2$ & $43.0 \%$ & $77.0 \%$ \\
\hline
\end{tabular}

Panel C2: Benchmark case, rounds 6 to $10, \bar{q}=11$

\begin{tabular}{|c|c|c|}
\hline Order type & $\begin{array}{c}\text { Call Auction following } \\
\text { nonbinding Preopening }\end{array}$ & $\begin{array}{c}\text { Call Auction following } \\
\text { Binding Preopening }\end{array}$ \\
\hline$B 0$ or $S 0$ & $1.0 \%$ & - \\
$B 1$ or $S 1$ & $54.0 \%$ & $24.0 \%$ \\
$B 2$ or $S 2$ & $45.0 \%$ & $76.0 \%$ \\
\hline
\end{tabular}

Panel C3: Benchmark case, rounds 11 to $15, \bar{q}=11$

\begin{tabular}{|c|c|c|}
\hline Order type & $\begin{array}{c}\text { Call Auction following } \\
\text { nonbinding Preopening }\end{array}$ & $\begin{array}{c}\text { Call Auction following } \\
\text { Binding Preopening }\end{array}$ \\
\hline$B 0$ or $S 0$ & - & $1.0 \%$ \\
$B 1$ or $S 1$ & $74.0 \%$ & $31.0 \%$ \\
$B 2$ or $S 2$ & $26.0 \%$ & $68.0 \%$ \\
\hline
\end{tabular}


Table 3: Matches

Panel A: Matches when $\bar{q}=9$

\begin{tabular}{|c|c|c|c|}
\hline Match & $\begin{array}{c}\text { Pure Call Auction } \\
\text { Without preopening }\end{array}$ & $\begin{array}{c}\text { Call Auction following } \\
\text { nonbinding Preopening }\end{array}$ & $\begin{array}{c}\text { Call Auction following } \\
\text { Binding Preopening }\end{array}$ \\
\hline$(S 1, B 1)$ & $66.7 \%$ & $82.2 \%$ & $78.3 \%$ \\
$(S 1, B 2)$ or $(S 2, B 1)$ & $29.3 \%$ & $17.2 \%$ & $17.8 \%$ \\
$(S 2, B 2)$ & $2.7 \%$ & $0.6 \%$ & $2.2 \%$ \\
with $B 0$ or $S 0$ & $1.3 \%$ & - & $1.7 \%$ \\
\hline
\end{tabular}

Panel B1: Matches when $\bar{q}=11$

\begin{tabular}{|c|c|c|c|}
\hline Match & $\begin{array}{c}\text { Pure Call Auction } \\
\text { Without preopening }\end{array}$ & $\begin{array}{c}\text { Call Auction following } \\
\text { nonbinding Preopening }\end{array}$ & $\begin{array}{c}\text { Call Auction following } \\
\text { Binding Preopening }\end{array}$ \\
\hline$(S 1, B 1)$ & $14.7 \%$ & $27.2 \%$ & $7.2 \%$ \\
$(S 1, B 2)$ or $(S 2, B 1)$ & $45.3 \%$ & $33.3 \%$ & $16.7 \%$ \\
$(S 2, B 2)$ & $40.0 \%$ & $39.4 \%$ & $75.0 \%$ \\
with $B 0$ or $S 0$ & - & - & $1.1 \%$ \\
\hline
\end{tabular}

Panel B2: Benchmark case, $\bar{q}=11$

\begin{tabular}{|c|c|c|}
\hline Match & $\begin{array}{c}\text { Call Auction following } \\
\text { nonbinding Preopening }\end{array}$ & $\begin{array}{c}\text { Call Auction following } \\
\text { Binding Preopening }\end{array}$ \\
\hline$(S 1, B 1)$ & $40.0 \%$ & $16.0 \%$ \\
$(S 1, B 2)$ or $(S 2, B 1)$ & $38.7 \%$ & $19.3 \%$ \\
$(S 2, B 2)$ & $18.7 \%$ & $64.0 \%$ \\
with $B 0$ or $S 0$ & $2.7 \%$ & $0.7 \%$ \\
\hline
\end{tabular}


Table 4: Preopening orders and following actions by the same player

Panel A: nonbinding preopening $\bar{q}=9$

\begin{tabular}{|c|c|c|c|r|}
\hline \multirow{2}{*}{ My play at $t=0$} & \multicolumn{3}{|c|}{ My play at $t=1$} & \multirow{2}{*}{ \% obs. } \\
\cline { 2 - 5 } & $B 0$ or $S 0$ & $B 1$ or $S 1$ & $B 2$ or $S 2$ & $7.2 \%$ \\
$B 1$ or $S 0$ & - & $92.3 \%$ & $7.7 \%$ & $29.2 \%$ \\
$B 2$ or $S 1$ & - & $86.7 \%$ & $13.3 \%$ & $2.6 \%$ \\
\hline
\end{tabular}

Panel B: Binding preopening $\bar{q}=9$

\begin{tabular}{|c|c|c|c|c|}
\hline \multirow{2}{*}{ My play at $t=0$} & \multicolumn{3}{|c|}{ My play at $t=1$} & \\
\cline { 2 - 4 } & $B 0$ or $S 0$ & $B 1$ or $S 1$ & $B 2$ or $S 2$ & obs. \\
\hline$B 0$ or $S 0$ & $1.1 \%$ & $93.2 \%$ & $5.7 \%$ & $77.8 \%$ \\
$B 1$ or $S 1$ & - & $100 \%$ & - & $15.6 \%$ \\
$B 2$ or $S 2$ & - & - & $100 \%$ & $6.7 \%$ \\
\hline
\end{tabular}

Panel C: nonbinding preopening $\bar{q}=11$

\begin{tabular}{|c|c|c|c|r|}
\hline \multirow{2}{*}{ My play at $t=0$} & \multicolumn{3}{|c|}{ My play at $t=1$} & \multirow{2}{*}{ \% obs. } \\
\cline { 2 - 4 } & $B 0$ or $S 0$ & $B 1$ or $S 1$ & $B 2$ or $S 2$ & $6.7 \%$ \\
$B 0$ or $S 0$ & - & $45.8 \%$ & $54.2 \%$ & or $S 1$ \\
$B 2$ or $S 2$ & - & $66.7 \%$ & $33.3 \%$ & $13.3 \%$ \\
& - & $39.9 \%$ & $60.1 \%$ & $80.0 \%$ \\
\hline
\end{tabular}

Panel D: Binding preopening $\bar{q}=11$

\begin{tabular}{|c|c|c|c|r|}
\hline \multirow{2}{*}{ My play at $t=0$} & \multicolumn{3}{|c|}{ My play at $t=1$} & \\
\cline { 2 - 5 } & $B 0$ or $S 0$ & $B 1$ or $S 1$ & $B 2$ or $S 2$ & \% obs. \\
\hline$B 0$ or $S 0$ & $1.3 \%$ & $28.1 \%$ & $70.6 \%$ & $44.4 \%$ \\
$B 1$ or $S 1$ & - & $100 \%$ & - & $3.1 \%$ \\
$B 2$ or $S 2$ & - & - & $100 \%$ & $52.5 \%$ \\
\hline
\end{tabular}

Panel E: Benchmark case, nonbinding preopening $\bar{q}=11$

\begin{tabular}{|c|c|c|c|r|}
\hline \multirow{2}{*}{ My play at $t=0$} & \multicolumn{3}{|c|}{ My play at $t=1$} & \multirow{2}{*}{ \% obs. } \\
\cline { 2 - 5 } & $B 0$ or $S 0$ & $B 1$ or $S 1$ & $B 2$ or $S 2$ & $3.3 \%$ \\
$B 1$ or $S 0$ & $10.0 \%$ & $70.0 \%$ & $20.0 \%$ & $22.3 \%$ \\
$B 2$ or $S 2$ & $1.5 \%$ & $76.1 \%$ & $22.4 \%$ & $26 \%$ \\
\hline
\end{tabular}

Panel F: Benchmark case, binding preopening $\bar{q}=11$

\begin{tabular}{|c|c|c|c|r|}
\hline \multirow{2}{*}{ My play at $t=0$} & \multicolumn{3}{|c|}{ My play at $t=1$} & \\
\cline { 2 - 5 } & $B 0$ or $S 0$ & $B 1$ or $S 1$ & $B 2$ or $S 2$ & \% obs. \\
\hline$B 0$ or $S 0$ & $0.7 \%$ & $38.2 \%$ & $61.0 \%$ & $45.3 \%$ \\
$B 1$ or $S 1$ & - & $100 \%$ & - & $8.7 \%$ \\
$B 2$ or $S 2$ & - & - & $100 \%$ & $46.0 \%$ \\
\hline
\end{tabular}


Table 5: Response to preopening orders

Panel A: nonbinding preopening $\bar{q}=9$

\begin{tabular}{|c|c|c|r|r|}
\hline \multirow{2}{*}{ My opponent at $t=0$} & \multicolumn{3}{|c|}{ My play at $t=1$} & \multirow{2}{*}{ \% obs. } \\
\cline { 2 - 5 } & $B 0$ or $S 0$ & $B 1$ or $S 1$ & $B 2$ or $S 2$ & $7.2 \%$ \\
$B 0$ or $S 0$ & - & $96.2 \%$ & $3.8 \%$ & $70.5 \%$ \\
\hline 1 or $S 1$ & - & $89.5 \%$ & $10.2 \%$ \\
$B 2$ or $S 2$ & - & $90.8 \%$ & $9.2 \%$ & $63.6 \%$ \\
\hline
\end{tabular}

Panel B: Binding preopening $\bar{q}=9$

\begin{tabular}{|c|c|c|c|c|}
\hline \multirow{2}{*}{ My opponent at $t=0$} & \multicolumn{3}{|c|}{ My play at $t=1$} & \multirow{2}{*}{ \% obs. } \\
\cline { 2 - 4 } & $B 0$ or $S 0$ & $B 1$ or $S 1$ & $B 2$ or $S 2$ & (15.0\% \\
$B 1$ or $S 0$ & $1.4 \%$ & $92.4 \%$ & $6.2 \%$ & $75.2 \%$ \\
$B 2$ or $S 2$ & - & $96.1 \%$ & $3.9 \%$ & $18.2 \%$ \\
\hline
\end{tabular}

Panel C: nonbinding preopening $\bar{q}=11$

\begin{tabular}{|c|c|c|c|r|}
\hline \multirow{2}{*}{ My opponent at $t=0$} & \multicolumn{3}{|c|}{ My play at $t=1$} & \multirow{2}{*}{ \% obs. } \\
\cline { 2 - 5 } & $B 0$ or $S 0$ & $B 1$ or $S 1$ & $B 2$ or $S 2$ & $6.7 \%$ \\
$B 0$ or $S 0$ & - & $41.7 \%$ & $58.3 \%$ & $13.3 \%$ \\
$B 1$ or $S 1$ & - & $85.4 \%$ & $14.6 \%$ & $13 \%$ \\
$B 2$ or $S 2$ & - & $37.2 \%$ & $62.8 \%$ & $80.0 \%$ \\
\hline
\end{tabular}

Panel D: Binding preopening $\bar{q}=11$

\begin{tabular}{|c|c|c|c|r|}
\hline \multirow{2}{*}{ My opponent at $t=0$} & \multicolumn{3}{|c|}{ My play at $t=1$} & \\
\cline { 2 - 5 } & $B 0$ or $S 0$ & $B 1$ or $S 1$ & $B 2$ or $S 2$ & \% obs. \\
\hline$B 0$ or $S 0$ & $1.7 \%$ & $38.3 \%$ & $60.0 \%$ & $37.5 \%$ \\
$B 1$ or $S 1$ & - & $100.0 \%$ & - & $3.8 \%$ \\
$B 2$ or $S 2$ & $1.1 \%$ & $17.0 \%$ & $81.9 \%$ & $58.8 \%$ \\
\hline
\end{tabular}

Panel E: Benchmark case, nonbinding preopening $\bar{q}=11$

\begin{tabular}{|c|c|c|c|r|}
\hline \multirow{2}{*}{ My opponent at $t=0$} & \multicolumn{3}{|c|}{ My play at $t=1$} & \multirow{2}{*}{ \% obs. } \\
\cline { 2 - 5 } & $B 0$ or $S 0$ & $B 1$ or $S 1$ & $B 2$ or $S 2$ & $3.3 \%$ \\
$B 1$ or $S 0$ & - & $100 \%$ & - & $22.3 \%$ \\
$B 2$ or $S 1$ & $3.0 \%$ & $82.1 \%$ & $14.9 \%$ & $2.6 \%$ \\
\hline
\end{tabular}

Panel F: Benchmark case, binding preopening $\bar{q}=11$

\begin{tabular}{|c|c|c|c|r|}
\hline \multirow{2}{*}{ My opponent at $t=0$} & \multicolumn{3}{|c|}{ My play at $t=1$} & \\
\cline { 2 - 5 } & $B 0$ or $S 0$ & $B 1$ or $S 1$ & $B 2$ or $S 2$ & \% obs. \\
\hline$B 0$ or $S 0$ & $1.8 \%$ & $66.1 \%$ & $32.1 \%$ & $41.2 \%$ \\
$B 1$ or $S 1$ & - & $81.8 \%$ & $18.2 \%$ & $8.1 \%$ \\
$B 2$ or $S 2$ & - & $8.7 \%$ & $91.3 \%$ & $50.7 \%$ \\
\hline
\end{tabular}


Table 6: Evolution of response to preopening orders

The first 5 rounds were played with $\bar{q}=11$, the next 5 rounds with $\bar{q}=9$, and the last 5 rounds with $\bar{q}=11$.

Panel A: Rounds 1 to $5, \bar{q}=11$

\begin{tabular}{|c|c|c|c|c|c|c|}
\hline \multirow{2}{*}{ My opponent } & \multicolumn{4}{|c|}{ Ponbinding } & \multicolumn{3}{c|}{ Minding } \\
\cline { 2 - 7 } & \multicolumn{3}{|c|}{ My play at $t=1$} & \multicolumn{3}{c|}{ My at $t=1$} \\
\cline { 2 - 7 } at $t=0$ & $B 0$ or $S 0$ & $B 1$ or $S 1$ & $B 2$ or $S 2$ & $B 0$ or $S 0$ & $B 1$ or $S 1$ & $B 2$ or $S 2$ \\
\hline$B 0$ or $S 0$ & - & $50.0 \%$ & $50.0 \%$ & - & $43.3 \%$ & $56.7 \%$ \\
$B 1$ or $S 1$ & - & $77.8 \%$ & $22.2 \%$ & - & $100.0 \%$ & - \\
$B 2$ or $S 2$ & - & $30.4 \%$ & $69.6 \%$ & - & $29.6 \%$ & $70.4 \%$ \\
\hline
\end{tabular}

Panel B: Rounds 6 to $10, \bar{q}=9$

\begin{tabular}{|c|c|c|c|c|c|c|}
\hline \multirow{2}{*}{ My opponent } & \multicolumn{4}{|c|}{ nonbinding } & \multicolumn{3}{c|}{ Binding } \\
\cline { 2 - 7 } & \multicolumn{3}{|c|}{ My play at $t=1$} & \multicolumn{3}{c|}{ My play at $t=1$} \\
\cline { 2 - 7 } at $t=0$ & $B 0$ or $S 0$ & $B 1$ or $S 1$ & $B 2$ or $S 2$ & $B 0$ or $S 0$ & $B 1$ or $S 1$ & $B 2$ or $S 2$ \\
\hline$B 0$ or $S 0$ & - & $90.0 \%$ & $10.0 \%$ & $1.4 \%$ & $95.7 \%$ & $2.9 \%$ \\
$B 1$ or $S 1$ & - & $100.0 \%$ & - & - & $100.0 \%$ & - \\
$B 2$ or $S 2$ & - & $89.0 \%$ & $11.0 \%$ & - & $100.0 \%$ & - \\
\hline
\end{tabular}

Panel C: Rounds 11 to $15, \bar{q}=11$

\begin{tabular}{|c|c|c|c|c|c|c|}
\hline \multirow{2}{*}{\begin{tabular}{c} 
My opponent \\
\cline { 2 - 7 } at $t=0$
\end{tabular}} & \multicolumn{3}{|c|}{ Monbinding } & \multicolumn{3}{c|}{ Preopening } \\
\cline { 2 - 7 } & $B 0$ or $S 0$ & $B 1$ or $S 1$ & $B 2$ or $S 2$ & $B 0$ or $S 0$ & $B 1$ or $S 1$ & $B 2$ or $S 2$ \\
\hline$B 0$ or $S 0$ & - & $14.3 \%$ & $85.7 \%$ & - & $40.0 \%$ & $60.0 \%$ \\
$B 1$ or $S 1$ & - & $92.9 \%$ & $7.1 \%$ & - & - & - \\
$B 2$ or $S 2$ & - & $38.4 \%$ & $61.6 \%$ & $2.9 \%$ & $17.1 \%$ & $80.0 \%$ \\
\hline
\end{tabular}


Table 7: Evolution of response to preopening orders

The first 5 rounds were played with $\bar{q}=9$, the next 5 rounds with $\bar{q}=11$, and the last 5 rounds with $\bar{q}=9$.

Panel A: Rounds 1 to $5, \bar{q}=9$

\begin{tabular}{|c|c|c|c|c|c|c|}
\hline \multirow{2}{*}{ My opponent } & \multicolumn{4}{|c|}{ nonbinding } & \multicolumn{3}{c|}{ Binding } \\
\cline { 2 - 7 } & \multicolumn{3}{|c|}{ My play at $t=1$} & \multicolumn{3}{c|}{ My at $t=1$} \\
\cline { 2 - 7 } at $t=0$ & $B 0$ or $S 0$ & $B 1$ or $S 1$ & $B 2$ or $S 2$ & $B 0$ or $S 0$ & $B 1$ or $S 1$ & $B 2$ or $S 2$ \\
\hline$B 0$ or $S 0$ & - & $100.0 \%$ & - & $1.6 \%$ & $82.3 \%$ & $16.1 \%$ \\
$B 1$ or $S 1$ & - & $83.7 \%$ & $16.3 \%$ & - & $89.5 \%$ & $10.5 \%$ \\
$B 2$ or $S 2$ & - & $90.1 \%$ & $9.9 \%$ & - & $85.7 \%$ & $14.3 \%$ \\
\hline
\end{tabular}

Panel B: Rounds 6 to $10, \bar{q}=11$

\begin{tabular}{|c|c|c|c|c|c|c|}
\hline \multirow{2}{*}{ My opponent } & \multicolumn{4}{|c|}{ Ponbinding } & \multicolumn{3}{c|}{ Binding } \\
\cline { 2 - 7 } & \multicolumn{3}{|c|}{ My play at $t=1$} & \multicolumn{3}{c|}{ Myy at $t=1$} \\
\cline { 2 - 7 } at $t=0$ & $B 0$ or $S 0$ & $B 1$ or $S 1$ & $B 2$ or $S 2$ & $B 0$ or $S 0$ & $B 1$ or $S 1$ & $B 2$ or $S 2$ \\
\hline$B 0$ or $S 0$ & - & $57.1 \%$ & $42.9 \%$ & $5.0 \%$ & $30.0 \%$ & $65.0 \%$ \\
$B 1$ or $S 1$ & - & $87.5 \%$ & $12.5 \%$ & - & $100.0 \%$ & - \\
$B 2$ or $S 2$ & - & $42.3 \%$ & $57.7 \%$ & - & $6.3 \%$ & $93.8 \%$ \\
\hline
\end{tabular}

Panel C: Rounds 11 to $15, \bar{q}=9$

\begin{tabular}{|c|c|c|c|c|c|c|}
\hline \multirow{2}{*}{ My opponent } & \multicolumn{4}{|c|}{ Ponbinding } & \multicolumn{3}{c|}{ Minding } \\
\cline { 2 - 7 } & \multicolumn{3}{|c|}{ My play at $t=1$} & & \multicolumn{3}{c|}{ My at $t=1$} \\
\cline { 2 - 7 } at $t=0$ & $B 0$ or $S 0$ & $B 1$ or $S 1$ & $B 2$ or $S 2$ & $B 0$ or $S 0$ & $B 1$ or $S 1$ & $B 2$ or $S 2$ \\
\hline$B 0$ or $S 0$ & - & $100.0 \%$ & - & $1.3 \%$ & $97.4 \%$ & $1.3 \%$ \\
$B 1$ or $S 1$ & - & $90.7 \%$ & $9.3 \%$ & - & $100.0 \%$ & - \\
$B 2$ or $S 2$ & - & $94.0 \%$ & $6.0 \%$ & - & $100.0 \%$ & - \\
\hline
\end{tabular}


Table 8: Evolution of response to preopening orders

Benchmark case: the 15 rounds were played with $\bar{q}=11$.

Panel A: Rounds 1 to $5, \bar{q}=11$

\begin{tabular}{|c|c|c|c|c|c|c|}
\hline \multirow{2}{*}{\begin{tabular}{c} 
My opponent \\
\cline { 2 - 7 } at $t=0$
\end{tabular}} & \multicolumn{3}{|c|}{ nonbinding } & \multicolumn{3}{c|}{ Minding } \\
\cline { 2 - 7 } & $B 0$ or $S 0$ & $B 1$ or $S 1$ & $B 2$ or $S 2$ & $B 0$ or $S 0$ & $B 1$ or $S 1$ & $B 2$ or $S 2$ \\
\hline$B 0$ or $S 0$ & - & $100.0 \%$ & - & - & $55.0 \%$ & $45.0 \%$ \\
$B 1$ or $S 1$ & $7.4 \%$ & $70.4 \%$ & $22.2 \%$ & - & $100 \%$ & - \\
$B 2$ or $S 2$ & $1.4 \%$ & $46.5 \%$ & $52.1 \%$ & - & $4.0 \%$ & $96.0 \%$ \\
\hline
\end{tabular}

Panel B: Rounds 6 to $10, \bar{q}=11$

\begin{tabular}{|c|c|c|c|c|c|c|}
\hline \multirow{2}{*}{\begin{tabular}{c} 
My opponent \\
\cline { 2 - 7 } at $t=0$
\end{tabular}} & \multicolumn{3}{|c|}{ nonbinding } & \multicolumn{3}{c|}{ Minding } \\
\cline { 2 - 7 } & \multicolumn{3}{|c|}{ My play at $t=1$} & \multicolumn{3}{c|}{ My at $t=1$} \\
\hline$B 0$ or $S 0$ & - & $B 1$ or $S 1$ & $B 2$ or $S 2$ & $B 0$ or $S 0$ & $B 1$ or $S 1$ & $B 2$ or $S 2$ \\
$B 1$ or $S 1$ & - & $90.5 \%$ & - & - & $65.0 \%$ & $35.0 \%$ \\
$B 2$ or $S 2$ & $1.3 \%$ & $42.1 \%$ & $56.6 \%$ & - & $75.0 \%$ & $25.0 \%$ \\
\cline { 2 - 7 } & &
\end{tabular}

Panel C: Rounds 11 to $15, \bar{q}=11$

\begin{tabular}{|c|c|c|c|c|c|c|}
\hline \multirow{2}{*}{ My opponent } & \multicolumn{4}{|c|}{ Preopening } \\
\cline { 2 - 7 } at $t=0$ & \multicolumn{3}{|c|}{ My play at $t=1$} & \multicolumn{3}{c|}{ Binding } \\
\cline { 2 - 7 } & $B 0$ or $S 0$ & $B 1$ or $S 1$ & $B 2$ or $S 2$ & $B 0$ or $S 0$ & $B 1$ or $S 1$ & $B 2$ or $S 2$ \\
\hline$B 0$ or $S 0$ & - & $100.0 \%$ & - & $6.3 \%$ & $81.3 \%$ & $12.5 \%$ \\
$B 1$ or $S 1$ & - & $89.5 \%$ & $10.5 \%$ & - & $75.0 \%$ & $25.0 \%$ \\
$B 2$ or $S 2$ & - & $68.4 \%$ & $31.6 \%$ & - & $17.4 \%$ & $82.6 \%$ \\
\hline
\end{tabular}

